\title{
FES in Europe and beyond: Current Translational Research
}

\author{
Christine Azevedo Coste (1), Winfried Mayr (2), Manfred Bijak (2), Antonio Musarò \\ $(3,4)$, Ugo Carraro (5)
}

(1) INRIA, LIRMM, Montpellier, France; (2) Center for Medical Physics and Biomedical Engineering / Medical University of Vienna, Austria; (3) Institute Pasteur Cenci-Bolognetti; DAHFMO-Unit of Histology and Medical Embryology, IIM; Sapienza University of Rome, Italy ;(4) Center for Life Nano Science@ Sapienza, Istituto Italiano di Tecnologia, Rome, Italy; (5) IRCCS Fondazione Ospedale San Camillo, Venice, Italy

This article is distributed under the terms of the Creative Commons Attribution Noncommercial License (CC BY-NC 4.0) which permits any noncommercial use, distribution, and reproduction in any medium, provided the original author(s) and source are credited.

\begin{abstract}
Capacity of adult neural and muscle tissues to respond to external Electrical Stimulation (ES) is the biological basis for the development and implementation of mobility impairment physiotherapy protocols and of related assistive technologies, e.g, Functional Electrical Stimulation (FES). All body tissues, however, respond to electrical stimulation and, indeed, the most successful application of FES is electrical stimulation of the heart to revert or limit effects of arrhythmias (Pace-makers and Defibrillators). Here, we list and discuss results of FES current research activities, in particular those presented at 2016 Meetings: the PaduaMuscleDays, the Italian Institute of Myology Meeting, the $20^{\text {th }}$ International Functional Electrical Stimulation Society (IFESS) conference held in Montpellier and the Vienna Workshop on FES. Several papers were recently e-published in the European Journal of Translational Myology as reports of meeting presentations. All the events and publications clearly show that FES research in Europe and beyond is alive and promisses translation of results into clinical management of a very large population of persons with deficiencies.
\end{abstract}

Key Words: FES, denervated muscle, mobility impairment, aging, prevention and assistive technology, rehabilitation, biomedical technology

Eur J Transl Myol 26 (4) 307-315

\begin{abstract}
Ability of neural and muscle tissues to respond to external Electrical Stimulation (ES) is the sound biological basis of established therapeutic managements of mobility impairments, assistive technology and of the current research activities aimed to extend its clinical applications. All the body tissues, however, respond to ES and, indeed, the most successful application of Functional Electrical Stimulation (FES), though known under other names or acronyms, is the electrical stimulation of the heart to revert or limit effects of arrhythmias (Pace-makers and Defibrillators). We would like to list and discuss here results of current research activities on FES, in particular those published in the European Journal of Translational Myology after presentation during the 2015 XI Meeting of the Italian Institute of Myology (IIM), ${ }^{1}$ the 2016 Spring PaduaMuscleDays, ${ }^{2}$ the 2016 Vienna FES Workshop and the 2016 International Conference of IFESS society held in Montpellier France. ${ }^{3}$

In Table 1 are listed the subtopics of FES research and applications published in the European Journal of
\end{abstract}

Translational Myology that will be discussed in the following sections. They are only some of a much longer list that represent the many subtopics of FES, i.e., i) Biological bases of FES for Neuromuscular Mobility Impairments; ii) FES for Arm, Leg and Body Motility; iii) FES for Swallowing, Micturition, Gastric function restoration; iv) FES as a countermeasure of muscle weakness and atrophy; v) FES and mechanical devices (wearable robots, cycles...); vi). FES for Pain Management; vii) Sensor interfaces to control FES (BCI, EMG, IMUand more); viii) FES advanced technology to improve efficiency and selectivity.

\section{XI Meeting of IIM, Italy and 2016 Spring PaduaMuscleDays}

Among other scientific topics, during the 2015 IIM meeting the molecular mechanisms of muscle atrophy, wasting and diseases were deeply discussed. One of the remarkable features of skeletal muscle is, indeed, the capacity to adapt its morphological, biochemical, and molecular properties in response to several events. 
Table 1. List of subtopics of Functional Electrical Stimulation research and management

1. Biological bases of FES for neuromuscular mobility impairments

2. FES for upper and lower body mobility

3. FES for swallowing, micturition, gastric and other vital functions

4. FES as a countermeasure of muscle atrophy, weakness and aging

5. FES combined with mechanical devices (wearable robots, cycles and more ...)

However, under pathological conditions skeletal muscle loses its adaptability, leading to atrophy and wasting. The continual synthesis and degradation of cell proteins is the result of normal intracellular metabolism and represents an important homeostatic function of muscle tissue. Muscle wasting, in contrast, is a process in which the delicate balance between anabolic and catabolic processes is impaired. In recent years, age-related diseases and disabilities have become of major interest and importance for health. The pathological process associated with aging is known as sarcopenia, characterized by a progressive loss of mobility and a decrease of the life quality. Society at large will benefit from delaying, as much as possible, the sarcopenia economic and social consequences. In elderly, muscles become atrophic (loss in muscle mass) and weaker (loss in muscle force), more susceptible to damage and consequently regenerate and recover more slowly than in younger individuals. ${ }^{4}$

During the IIM-Myology meeting, several signaling pathways have been discussed as key maintenance regulators of muscle mass or triggers of muscle wasting. ${ }^{1}$ Nevertheless, despite the new discoveries in this field, no effective therapies are still available. Therefore, it is of fundamental importance to gain greater knowledge about the cellular and molecular processes controlling this debilitating condition to find effective countermeasures. ${ }^{5}$ FES is one of the approaches that attracted much attention in the last 10 years, based on practical considerations: i) ES can be applied to people that cannot carry out normal physical activity; ii) it modulates similar factors associated with physical exercise; iii) it improves muscle mass and function in sedentary elderly people. In particular, it has been demonstrated that ES activates, at the level of skeletal muscle, the growth factor IGF-1, which in turn promotes anabolic pathways increasing protein synthesis while reducing protein degradation. IGF-1 and FES appear to be responsible for the increase in muscle performance. Interestingly, ES, similarly to physical exercise, attenuates the functional decline associated with aging, improving muscle strength and mass, maintaining the overall size of muscle fibers (decreasing during aging), activating satellite cells and guaranteeing muscle adaption. ${ }^{6}$ Based on several evidences, we can also speculate that FES mimics the effects of endurance training, since they do not induce muscle damage, and activate comparable molecular networks.

Many of these mechanisms were discussed in recent papers published in the European Journal of Translational Myology and during the 2016Spring PaduaMuscleDays as the main determinants of the positive effects of physical exercise and FES when applied to therapeutic and rehabilitation strategies aimed to prevent or revert the consequences of aging and mobility impairments. ${ }^{2,3,7-15}$

\section{0th Conference of the International Functional Electrical Stimulation Society, IFESS - 2016}

The International Functional Electrical Stimulation Society (IFESS) is an inter-professional and collaborative organization, whose main objective is promotion of research, applications and understanding of electrical stimulation as it is utilized in the field of medicine. ${ }^{3}$

The theme of the 20th IFESS conference, organized in Montpellier, France in 2016 by INRIA institute and Montpellier university was «Hybrid Approaches of IFESS». The idea being to highlight ongoing research activities associating FES to other assistive approaches such as exoskeletons or central nervous system (CNS) stimulation. The notion of hybridity can also be seen from the perspective of the multidisciplinary face of the field. Three special sessions were dedicated specifically to this theme with articles associating FES to 1) wearable robotics, 2) CNS stimulation and 3) cycling devices. Electrical stimulation can be applied in a large panel of situations and some of the emerging applications have been presented in the special session: "Emerging FES interventions, with original and promising studies". Electrical stimulation activates both efferent and afferent pathways. This property is extremely appealing in the context of functional rehabilitation and neurological recovery. The engagement of patients is mandatory to increase the potential of the training. This was the object of the special session "FES and fun" which explores different approaches to motivate the patients to actively participate into their rehabilitation protocol. In the regular sessions, articles insisted in the recent advances in technology to improve stimulation efficiency and selectivity, to explore new modalities and applications of FES. Engineers and Clinicians demonstrated in their articles the importance and potential of this very active research field. We wish to thank all authors of the articles that have contributed to EJTM (Tables 2 to7) and for making the Ejtm Special Section on 2016 IFESS Conference an exciting and intriguing read. ${ }^{9,16-64}$ 
Table 2. European Journal of Translational Myology, 2016. FES papers: Subtopic 1. Biological bases of FES for neuromuscular mobility impairments

Review Carraro U, Kern H. Severely atrophic human muscle fibers with nuclear misplacement survive many years of permanent denervation. Eur J Transl Myol 2016;26:76-80. ${ }^{15}$

Article Zampieri S, Mosole S, Löfler S, et al. Physical Exercise in Aging: Nine Weeks of Leg Press or Electrical Stimulation Training in 70 Years Old Sedentary Elderly People. Eur J Transl Myol 2015; 25: 237-242. doi: 10.4081/ejtm.2015.5374. ${ }^{9}$

Review Barberi L, Scicchitano BM, Musaro A. Molecular and Cellular Mechanisms of Muscle Aging and Sarcopenia and Effects of Electrical Stimulation in Seniors. Eur J Transl Myol 2015;25:231-6. doi: 10.4081/ejtm.2015.5227. ${ }^{16}$

Article Tramonti C, Rossi B, Chisari C. Extensive functional evaluations to monitor aerobic training in Becker Muscular Dystrophy: A case report. Eur J Transl Myol 2016;26:81-6. ${ }^{17}$

Article Hiroux C, Vandoorne T, Koppo K, De Smet S, Hespel P, Berardi E. Physical activity counteracts tumor cell growth in colon carcinoma C26-injected muscles: an interim report. Eur J Transl Myol 2016;26:67-75. ${ }^{18}$

Review Coletti D, Daou N, Hassani M, Li Z, Parlakian A, Serum Response Factor in muscle tissues: from development to ageing. Eur J Transl Myol 2016;26:87-92. ${ }^{19}$

Article Guiho T, Azevedo Coste C, Delleci C, Chenu J-P, Vignes J-R, Bauchet L, Guiraud D. An intermediate animal model of spinal cord stimulation. Eur J Transl Myol 2016;26:150-4. ${ }^{20}$

Article Totzeck A, Mummel P, Kastrup O, Hagenacker T. Clinical features of neuromuscular disorders in patients with N-type voltage-gated calcium channel antibodies. Eur J Transl Myol 2016;26:301-6. ${ }^{21}$

Article Carotenuto F, Coletti D, Di Nardo P, Teodori L. $\alpha$-linolenic acid reduces TNF-induced apoptosis in C2C12 myoblasts by regulating apoptotic proteins expression. Eur J Transl Myol 2016;26:317-22. ${ }^{22}$

Article Lavorato M, Gupta PK, Hopkins PM, Franzini-Armstrong C. Skeletal muscle microalterations in patients carrying Malignant Hyperthermia-related mutations of the e-c coupling machinery. Eur J Transl Myol 2016;26:323-32. ${ }^{23}$

Review Scicchitano BM, Sica G, Musarò A. Stem cells and tissue niche: two faces of the same coin of muscle regeneration. Eur J Transl Myol 2016;26:333-8. ${ }^{15}$

\section{2th Vienna International Workshop on FES, September 8th-9th, 2016}

The "Vienna Workshop on Functional Electrical Stimulation" was held the first time in 1983 in Vienna, Austria. Since then it is organized by the Center for Medical Physics and Biomedical Engineering (former: Center for Biomedical Engineering and Physics), the Medical University of Vienna and the Austrian Society for Biomedical Engineering every three years in Vienna or locations close to Vienna. This scientific conference provides a platform for researchers to present and discuss their recent work whilst visitors can expect a representative and actual overview of the state of the art of FES. Traditionally, parallel sessions are avoided. Since the 10th Workshop (2010) all conference proceedings are available on DVD: "30 years of FES history on one click" (http://fesworkshop.org).

This year's Workshop was held at the renovated Campus of the Medical University Vienna, a place with a long history in medical research.
The conference started with two Pre-Conference Courses "FES of Denervated Muscles - An Essential Therapeutic Option after Peripheral Nerve Lesion", (Organizers: Mayr W., Krenn M., Biowski P., all from Vienna, Austria) and "Non invasive posterior root stimulation for assessment and modulation of spasticity and motor control" (Organizers: Mayr W., Krenn M., both Vienna, Austria and Dimitrijevic M., Houston, TX, USA) designed as hands - on workshops with a comprehensive introduction on physiological, clinical and technical basics, safety issues, handling of equipment, guidelines and protocols.

As FES of denervated muscles differs fundamentally from classical neuromuscular ES, the main particularities were addressed in an open interactive discussion, scientifically based on the strong clinical, functional and structural results of the EU Program $\operatorname{RISE}^{6-8} \cdot 6-8$ 
Table 3. European Journal of Translational Myology, 2016. FES papers of Subtopic 2. Body and leg motility

Article Laubacher M, Aksöz EA, Binder-Macleod S, Hunt KJ. Comparison of proximally versus distally placed spatially distributed sequential stimulation electrodes in a dynamic knee extension task. Eur J Transl Myol 2016;26:110-115. ${ }^{26}$

Article Schweigmann M, Kirchhoff F, Koch KP. Modeling and Simulations in Time Domain of a Stimulation Setup for Cortical Applications. Eur J Transl Myol 2016;26:116-21. ${ }^{27}$

Article Sijobert B, Azevedo-Coste C, Andreu D, Verna C, Geny C. Effects of sensitive electrical stimulation based cueing in Parkinson's disease: a preliminary study. Eur J Transl Myol 2016;26:122-8. ${ }^{28}$

Article Kumar D, Verma S, Bhattacharya S, Lahiri U. Audio-visual stimulation in conjunction with functional electrical stimulation to address upper limb and lower limb movement disorder. Eur J Transl Myol 2016;26:140-4. ${ }^{29}$

Article Kumar D, Dutta A, Das A, Lahiri U. Engagement sensitive visual stimulation. Eur J Transl Myol 2016;26:145-9..$^{30}$

Article Bhattacharyya S, Clerc M, Hayashibe M. A study on the effect of electrical stimulation as a user stimuli for motor imagery classification in Brain-Machine Interface. Eur J Transl Myol 2016;26:165-8. ${ }^{31}$

Article Muthalib M, Kerr G, Nosaka K, Perrey S. Local muscle metabolic demand induced by neuromuscular electrical stimulation and voluntary contractions at different force levels: a NIRS study. Eur J Transl Myol 2016;26:169-74.32

Article Malešević J, Štrbac M, Isaković M, Kojić V, Konstantinović L, Vidaković A, Dedijer S, Kostić M, Keller T. Evolution of surface motor activation zones in hemiplegic patients during 20 sessions of FES therapy with multi-pad electrodes. Eur J Transl Myol 2016;26:175-80. ${ }^{33}$

Article Peri E, Ambrosini E, Pedrocchi A, Ferrigno G, Nava C, Longoni V, Monticone M, Ferrante S. Can FESaugmented active cycling training improve locomotion in post-acute elderly stroke patients? Eur J Transl Myol 2016;26:187-92. ${ }^{34}$

Article Li Z, Guiraud D, Andreu D, Fattal C, Gelis A, Hayashibe M. A hybrid functional electrical stimulation for real-time estimation of joint torque and closed-loop control of muscle activation. Eur J Transl Myol 2016;26:193-6. ${ }^{35}$

Article Araujo Guimarães J, Oliveira da Fonsec La, Cardoso dos Santos-Couto-Paz C, Padilha Lanari Bó A, Fattal C, Azevedo-Coste C, Fachin-Martins E. Towards parameters and protocols to recommend FES-Cycling in cases of paraplegia: a preliminary report. Eur J Transl Myol 2016;26:209-14. ${ }^{36}$

Article Dali M, Rossel O, Guiraud D. Fast simulation and optimization tool to explore selective neural stimulation. Eur J Transl Myol 2016;26:215-8. ${ }^{37}$

Article Cho W, Sabathiel N, Ortner R, Lechner A, Irimia DC, Allison BZ, Edlinger G, Guger Ch. Paired Associative Stimulation using Brain-Computer Interfaces for Stroke Rehabilitation: A Pilot study. Eur J Transl Myol 2016;26:219-22. ${ }^{38}$

Article Aksöz EA, Laubacher M, Binder-Macleod S, Kenneth J. Hunt Effect of stochastic modulation of inter-pulse interval during stimulated isokinetic leg extension. Eur J Transl Myol 2016;26:229-34. ${ }^{39}$

Article Julémont N, Nonclercq A, Delchambre V, Vanhoestenberghe A. A study on cross-talk nerve stimulation: electrode placement and current leakage lid. Eur J Transl Myol 2016;26:239-43 . . $^{40}$

Article Dautrebande M, Doguet P, Gorza S-P, Delbeke J, Botquin Y, Nonclercq A. In vivo photonic stimulation of sciatic nerve with a 1470 nm Laser. Eur J Transl Myol 2016;26:244-8. ${ }^{41}$

Article Stratton K, Faghri PD. Electrically and hybrid-induced muscle activations: effects of muscle size and fiber type. Eur J Transl Myol 2016;26:249-54. ${ }^{42}$

Article Laursen CB, Nielsen JF, Andersen OK, Spaich EG. Feasibility of using Lokomat combined with functional electrical stimulation for the rehabilitation of foot drop. Eur J Transl Myol 2016;26:268-73. ${ }^{43}$

The goal was to train qualified medical staff to a level that allows confident, safe and efficient clinical application of the introduced methods.

The scientific program started with two special topics on Functional Rejuvenation in Aging and Electrical Stimulation in Neuromuscular Disorders. Then it continued with a special session where the outcomes of the EU project RETRAINER (http://www.retrainer.eu/) were introduced with enough time to get in touch with the project leaders and to try out first prototypes for robotic supported reaching and grasping training. 
Table 4. European Journal of Translational Myology, 2016. FES papers of Subtopic 3. Arm motility

Article Lopes ACG, Ochoa-Diaz C , Baptista RS, Fonseca LO, Fattal C, Azevedo Coste C, Bó APL, Fachin-Martins E. Electrical stimulation to reduce the overload in upper limbs during sitting pivot transfer in paraplegic: a preliminary study. Eur $\mathbf{J}$ Transl Myol 2016;26:278- 82. ${ }^{43}$

Article Isaković M, Belić M, Štrbac M, Popović I, Došen S, Farina D, Keller T. Electrotactile feedback improves performance and facilitates learning in the routine grasping task. Eur J Transl Myol 2016;26:197-202. ${ }^{44}$

Article Gui K, Yokoi H, DZhangD. Human-FES cooperative control for wrist movement: a preliminary study. Eur J Transl Myol 2016;26:235-8. ${ }^{45}$

Article Marquez-Chin C, Marquis A, Popovic MR. BCI-Triggered functional electrical stimulation therapy for upper limb. Eur J Transl Myol 2016;26:274-7. ${ }^{46}$

The following sessions covered findings in Basic Research, Neuromodulation, Rehabilitation strategies, FES Exercise and in the more hardware oriented part Technologies, Engineering, Sensors.

Three excellent keynote speakers provided insight into latest findings in FES and neighboring fields.

Jarvis J. (Liverpool, GB) introduced the potential of genomics, metabolomics and proteomics technologies to better understand cell biology in his talk "Neuromuscular cell biology and "omic technologies".

Lukanovič A. (Ljubljana, Slovenia) discussed "Neuromodulation in the treatment of pelvic floor dysfunctions" and Podesser B. (Vienna, Austria) talked about "Animal research in FES" and the related
Table 5. European Journal of Translational Myology, 2016. FES papers: Subtopic 3. FES for swallowing, and other applications

Article Schultheiss C, Schauer T, Nahrstaedt H, Seidl RO, Bieler J. Efficacy of EMG/BioimpedanceTriggered Functional Electrical Stimulation on Swallowing Performance. Eur J Transl Myol 2016;26:283-6. ${ }^{47}$

Article Riebold B, Nahrstaedt H, Schultheiss C, Seidl RO, SchauerT. Multisensor Classification System for Triggering FES in Order to Support Voluntary Swallowing. Eur J Transl Myol 2016;26:287-91. ${ }^{48}$

Article Lonys L, Vanhoestenberghe A, Huberty V, Hiernaux M, Cauche N, Julémont N, Debelle A, Huberland F, Acuña V, Godfraind $C$, Devière J, Delchambre A, Mathys $\mathrm{P}$, Nonclercq A. Design and implementation of a less invasive gastrostimulator. Eur $\mathbf{J}$ Transl Myol 2016;26:129-33. ${ }^{49}$

Article Andrews B, Shippen J, Armengol M, Gibbons R, Holderbaum W, Harwin W. A Design Method for FES Bone Health Therapy in SCI. Eur J Transl Myol 2016;26:297-300. ${ }^{50}$

possibilities and regulations.

Details of the program of the 12th Vienna International Workshop on FES, September 8th-9th, 2016 are available at the link: http://2016.fesworkshop.org/

\section{Conclusions}

Altogether, evidence demonstrates that FES basic, translational and clinical research in Europe and beyond is alive. Translation of results to clinical therapies for a large population of patients is much more than a hope.

\section{Author's contributions}

All authors equally organized the draft and wrote the typescript.

Table 6. European Journal of Translational Myology, 2016. FES papers of Subtopic 4. FES as a countermeasure of muscle weakness, atrophy and aging

Myo News XII IIM - Myology Meeting, October 1st to 4th 2015 - Reggio Emilia (Italy), Abstracts. Eur J Trans1 Myol 2016;26:2-24. ${ }^{1}$

Myo News 2016Spring PaduaMuscleDays, April 13th to 16th - Terme Euganee, Padova (Italy), Abstracts. Eur J Transl Myol 2016;26:37-60. ${ }^{2}$

Article Edmunds KJ, Gíslason MK, Arnadottir ID, Marcante A, Piccione F, Gargiulo P. Quantitative Computed Tomography and image analysis for advanced muscle assessment. Eur J Transl Myol 2016;26:93-100. ${ }^{51}$ 
Table 7. European Journal of Translational Myology, 2016. FES papers of Subtopic 6. FES Technology

\begin{abstract}
Article Salchow C, Valtin M, Seel T, Schauer T. A new semi-automatic approach to find suitable virtual electrodes in arrays using an interpolation strategy. Eur J Transl Myol 2016;26:134-9. ${ }^{52}$

Article Godfraind C, Debelle A, Lonys L, Acuña V, Doguet P, Nonclercq A. Inductive powering of subcutaneous stimulators: key parameters and their impact on the design methodology. Eur J Transl Myol 2016;26:155$60 .^{53}$

Article Oliveira A, Ordonez JS, Ashouri Vajari D, Eickenscheidt M, Stieglitz T. Laser-induced carbon pyrolysis of electrodes for neural interface systems. Eur J Transl Myol 2016;26:181-6. ${ }^{54}$

Article Godfraind C, Debelle A, Lonys L, Acuña V, Doguet P, Nonclercq A. Inductive powering of subcutaneous stimulators: key parameters and their impact on the design methodology. Eur J Transl Myol 2016;26:155$60 .^{55}$
\end{abstract}

Article Valtin M, Kociemba K, Behling C, Kuberski B, Becker S, Schauer T. RehaMovePro: A versatile mobile stimulation system for transcutaneous FES applications. Eur J Transl Myol 2016;26:203-8. ${ }^{56}$

Article Oliveira A, Ordonez JS, Ashouri Vajari D, Eickenscheidt M, Stieglitz T. Laser-induced carbon pyrolysis of electrodes for neural interface systems. Eur J Transl Myol 2016;26:181-6. ${ }^{57}$

Article Aqueveque P, Acuña V, Saavedra V, Debelle A, Lonys L, Julémont N, Huberland F, Godfraind C, Nonclercq A. Power strategy in DC/DC converters to increase efficiency of electrical stimulators. Eur J Transl Myol 2016;26:223-8. ${ }^{58}$

Article Julémont N, Nonclercq A, Delchambre V, Vanhoestenberghe A. A study on cross-talk nerve stimulation: electrode placement and current leakage lid. Eur J Transl Myol 2016;26:239-43 .59

Article Resquín F, Gonzalez-Vargas J, Ibáñez J, Brunetti F, Pons JL. Feedback error learning controller for functional electrical stimulation assistance in a hybrid robotic system for reaching rehabilitation. Eur $\mathbf{J}$ Transl Myol 2016;26:255-61. ${ }^{60}$

Article Aqueveque P, Sobarzo S, Saavedra F, Maldonado C, Gómez B. Android platform for realtime gait tracking using inertial measurement units. Eur J Transl Myol 2016;26:262-7. ${ }^{61}$

Article Laursen CB, Nielsen JF, Andersen OK, Spaich EG. Feasibility of using Lokomat combined with functional electrical stimulation for the rehabilitation of foot drop. Eur J Transl Myol 2016;26:268-73. ${ }^{62}$

Article Marquez-Chin C, Marquis A, Popovic MR. BCI-Triggered functional electrical stimulation therapy for upper limb. Eur J Transl Myol 2016;26:274-7. ${ }^{63}$

Article Debelle A, Hermans L, Bosquet M, Dehaeck S, Lonys L, Scheid B, Nonclercq A Vanhoestenberghe A. Soft Encapsulation of Flexible Electrical Stimulation Implant: Challenges and Innovations. Eur J Transl Myol 2016;26:292-6. ${ }^{64}$

\section{Acknowledgments}

CAC thanks the International Functional Electrical Stimulation society (IFESS) and INRIA for support. Work in the Laboratories of AM has been supported by Telethon (GGP14066) and Fondazione Roma. UC thanks the IRCCS Fondazione Ospedale San Camillo, Venice (Italy) for scientific support and hospitality.

\section{Conflict of Interest}

The authors declare no potential conflict of interests.

\section{Corresponding Author}

Ugo Carraro, Fondazione Ospedale San Camillo, IRCCS, Via Alberoni 70, I - 30126 Venice-Lido, Italy. e-mail: ugo.carraro@ospedalesancamillo.net

\section{E-mails of coauthors}

Christine Azevedo Coste: christine.azevedo@inria.fr Winfried Mayr: winfried.mayr@meduniwien.ac.at Manfred Bijak: manfred.bijak@meduniwien.ac.at Antonio Musaro: antonio.musaro@uniroma1.it

\section{References}

1. XII IIM - Myology Meeting, October 1st to 4th 2015 - Reggio Emilia, Italy, Abstracts. Eur J Transl Myol 2016;26:2-24.

2. 2016Spring PaduaMuscleDays, April $13^{\text {rd }}$ to $16^{\text {th }}$, Terme Euganee, Padova, Italy, Abstracts. Eur J Transl Myol 2016;26:37-60.

3. Azevedo-Coste C, Popovic MR, Mayr W. Ejtm Special: 20th Conference of the International 
Functional Electrical Stimulation Society, IFESS. Eur J Transl Myol 2016;26:109.

4. Carraro U, Kern H, Gava P, et al. Biology of Muscle Atrophy and of its Recovery by FES in Aging and Mobility Impairments: Roots and ByProducts. Eur J Transl Myol. 2015;25:221-30. doi: 10.4081/ejtm.2015.5272.

5. Carraro U, Kern H, Gava P, et al. Recovery from muscle weakness by exercise and FES: lessons from Masters, active or sedentary seniors and SCI patients. Aging Clin Exp Res 2016 Sep 3. [Epub ahead of print] Review.

6. Kern H, Boncompagni S, Rossini K, et al. Longterm denervation in humans causes degeneration of both contractile and excitation- contraction coupling apparatus, which is reversible by functional electrical stimulation (FES). A role for myofiber regeneration? J Neuropathol Exp Neurol 2004;63:919-31.

7. Boncompagni S, Kern $\mathrm{H}$, Rossini $\mathrm{K}$, et al. Structural differentiation of skeletal muscle fibers in the absence of innervation in humans. Proc Natl Acad Sci U S A. 2007; 104: 19339- 19344.

8. Kern H, Carraro U, Adami N, et al. Home-based Functional Electrical Stimulation (h-b FES) recovers permanently denervated muscles in paraplegic patients with complete lower motor neuron lesion. Neurorehab Neur Rep 2010;24:70921.

9. Zampieri S, Mosole S, Löfler S, et al. Physical Exercise in Aging: Nine Weeks of Leg Press or Electrical Stimulation Training in 70 Years Old Sedentary Elderly People. Eur J Transl Myol 2015; 25: 237-242. doi: 10.4081/ejtm.2015.5374.

10. Musarò A, Giacinti C, Pelosi L, et al. Stem Cellmediated muscle regeneration and repair in aging and neuromuscular diseases. Eur J Histochem 2007;51:35-43.

11. Toschi A, Severi A, Coletti D, et al. Skeletal muscle regeneration in mice is stimulated by local overexpression of V1a-vasopressin receptor. Mol Endocrinol 2011;25:1661-73.

12. Musarò A. The Basis of muscle regeneration. Advances in Biology 2014, 2014:1-16.

13. Carraro U, Boncompagni S, Gobbo V, et al. Persistent muscle fiber regeneration in long term dener vation. Past, present, future. Eur J Transl Myol. 2015;25:77-92. Doi: 10.4081/bam. 2015.2.77

14. Kern H, Barberi L, Löfler S, et al. Electrical stimulation counteracts muscle decline in seniors. Front Aging Neurosci. 2014;6:189. doi: 10.3389/fnagi.2014.00189.

15. Carraro U, Kern H. Severely atrophic human muscle fibers with nuclear misplacement survive many years of permanent denervation. Eur J Transl Myol 2016;26:76-80.
16. Barberi L, Scicchitano BM, Musaro A. Molecular and Cellular Mechanisms of Muscle Aging and Sarcopenia and Effects of Electrical Stimulation in Seniors. Eur J Transl Myol 2015;25:231-6. doi: 10.4081/ejtm.2015.5227.

17. Tramonti C, Rossi B, Chisari C. Extensive functional evaluations to monitor aerobic training in Becker Muscular Dystrophy: A case report. Eur J Transl Myol 2016;26:81-6.

18. Hiroux C, Vandoorne T, Koppo K, et al. Physical activity counteracts tumor cell growth in colon carcinoma C26-injected muscles: an interim report. Eur J Transl Myol 2016;26:67-75.

19. Coletti D, Daou N, Hassani M, Li Z, Parlakian A, Serum Response Factor in muscle tissues: from development to ageing. Eur J Transl Myol 2016;26:87-92.

20. Guiho T, Azevedo Coste C, Delleci C, Chenu J-P, Vignes J-R, Bauchet L, Guiraud D. An intermediate animal model of spinal cord stimulation. Eur J Transl Myol 2016;26:150-4.

21. Totzeck A, Mummel P, Kastrup O, Hagenacker T. Clinical features of neuromuscular disorders in patients with N-type voltage-gated calcium channel antibodies. Eur J Transl Myol 2016;26:301-6.

22. Carotenuto F, Coletti D, Di Nardo P, Teodori L. $\alpha$ linolenic acid reduces TNF-induced apoptosis in $\mathrm{C} 2 \mathrm{C} 12$ myoblasts by regulating expression of apoptotic proteins. Eur J Transl Myol 2016;26:317-22.

23. Lavorato M, Gupta PK, Hopkins PM, FranziniArmstrong C. Skeletal muscle microalterations in patients carrying Malignant Hyperthermia-related mutations of the e-c coupling machinery. Eur $\mathbf{J}$ Transl Myol 2016;26:323-32.

24. Scicchitano BM, Sica G, Musarò A. Stem cells and tissue niche: two faces of the same coin of muscle regeneration. Eur J Transl Myol 2016;26:333-8.

25. Laubacher M, Aksöz EA, Binder-Macleod S, Hunt KJ. Comparison of proximally versus distally placed spatially distributed sequential stimulation electrodes in a dynamic knee extension task. Eur J Transl Myol 2016;26:110-5.

26. Schweigmann M, Kirchhoff F, Koch KP. Modeling and Simulations in Time Domain of a Stimulation Set-up for Cortical Applications. Eur J Transl Myol 2016;26:116-21.

27. Sijobert B, Azevedo-Coste C, Andreu D, Verna C, Geny C. Effects of sensitive electrical stimulation based cueing in Parkinson's disease: a preliminary study. Eur J Transl Myol 2016;26:122-8.

28. Kumar D, Verma S, Bhattacharya S, Lahiri U. Audio-visual stimulation in conjunction with functional electrical stimulation to address upper limb and lower limb movement disorder. Eur J Transl Myol 2016;26:140-4. 
29. Kumar D, Dutta A, Das A, Lahiri U. Engagement sensitive visual stimulation. Eur J Transl Myol 2016;26:145-9.

30. Bhattacharyya S, Clerc M, Hayashibe M. A study on the effect of electrical stimulation as a user stimuli for motor imagery classification in BrainMachine Interface. Eur J Transl Myol 2016;26:165-8.

31. Muthalib M, Kerr G, Nosaka K, Perrey S. Local muscle metabolic demand induced by neuromuscular electrical stimulation and voluntary contractions at different force levels: a NIRS study. Eur J Transl Myol 2016;26:169-74.

32. Malešević J, Štrbac M, Isaković $M$, et al. Evolution of surface motor activation zones in hemiplegic patients during 20 sessions of FES therapy with multi-pad electrodes. Eur J Transl Myol 2016;26:175-80.

33. Peri E, Ambrosini E, Pedrocchi A, et al. Can FESaugmented active cycling training improve locomotion in post-acute elderly stroke patients? Eur J Transl Myol 2016;26:187-92.

34. Li Z, Guiraud D, Andreu D, et al. A hybrid functional electrical stimulation for real-time estimation of joint torque and closed-loop control of muscle activation. Eur J Transl Myol 2016;26:193-6.

35. Araujo Guimarães J, Oliveira da Fonsec L, Cardoso dos Santos-Couto-Paz C, et al. Towards parameters and protocols to recommend FESCycling in cases of paraplegia: a preliminary report. Eur J Transl Myol 2016;26:209-14.

36. Dali M, Rossel O, Guiraud D. Fast simulation and optimization tool to explore selective neural stimulation. Eur J Transl Myol 2016;26:215-8.

37. Cho W, Sabathiel N, Ortner R, et al. Paired Associative Stimulation using Brain-Computer Interfaces for Stroke Rehabilitation: A Pilot study. Eur J Transl Myol 2016;26:219-22.

38. Aksöz EA, Laubacher M, Binder-Macleod S, Hunt KJ. Effect of stochastic modulation of inter-pulse interval during stimulated isokinetic leg extension. Eur J Transl Myol 2016;26:229-34.

39. Julémont $\mathrm{N}$, Nonclercq A, Delchambre $\mathrm{V}$, Vanhoestenberghe A. A study on cross-talk nerve stimulation: electrode placement and current leakage lid. Eur J Transl Myol 2016;26:239-43.

40. Dautrebande $\mathrm{M}$, Doguet P, Gorza S-P, et al. In vivo photonic stimulation of sciatic nerve with a 1470 nm Laser. Eur J Transl Myol 2016;26:244-8.

41. Stratton K, Faghri PD. Electrically and hybridinduced muscle activations: effects of muscle size and fiber type. Eur J Transl Myol 2016;26:249-54.

42. Laursen CB, Nielsen JF, Andersen OK, Spaich EG. Feasibility of using Lokomat combined with functional electrical stimulation for the rehabilitation of foot drop. Eur J Transl Myol 2016;26:268-73.
43. Lopes ACG, Ochoa-Diaz C, Baptista RS, et al. Electrical stimulation to reduce the overload in upper limbs during sitting pivot transfer in paraplegic: a preliminary study. Eur J Transl Myol 2016;26:278-82.

44. Isaković M, Belić M, Štrbac M, et al. Electrotactile feedback improves performance and facilitates learning in the routine grasping task. Eur J Transl Myol 2016;26:197-202.

45. Gui K, Yokoi H, Zhang D. Human-FES cooperative control for wrist movement: a preliminary study. Eur J Transl Myol 2016;26:235-8.

46. Marquez-Chin C, Marquis A, Popovic MR. BCITriggered functional electrical stimulation therapy for upper limb. Eur J Transl Myol 2016;26:274-7.

47. Schultheiss C, Schauer T, Nahrstaedt H, Seidl RO, Bieler J. Efficacy of EMG/BioimpedanceTriggered Functional Electrical Stimulation on Swallowing Performance. Eur J Transl Myol 2016;26:283-6.

48. Riebold B, Nahrstaedt H, Schultheiss C, et al. Multisensor Classification System for Triggering FES in Order to Support Voluntary Swallowing. Eur J Transl Myol 2016;26:287-91.

49. Lonys L, Vanhoestenberghe A, Huberty V, et al. Design and implementation of a less invasive gastrostimulator. Eur J Transl Myol 2016;26:12933.

50. Andrews B, Shippen J, Armengol M, et al. A Design Method for FES Bone Health Therapy in SCI. Eur J Transl Myol 2016;26:297-300.

51. Edmunds KJ, Gíslason MK, Arnadottir ID, et al. Quantitative Computed Tomography and image analysis for advanced muscle assessment. Eur J Transl Myol 2016;26:93-100.

52. Salchow C, Valtin M, Seel T, Schauer T. A new semi-automatic approach to find suitable virtual electrodes in arrays using an interpolation strategy. Eur J Transl Myol 2016;26:134-9.

53. Godfraind C, Debelle A, Lonys L, et al. Inductive powering of subcutaneous stimulators: key parameters and their impact on the design methodology. Eur J Transl Myol 2016;26:155-60.

54. Oliveira A, Ordonez JS, Ashouri Vajari D, et al. Laser-induced carbon pyrolysis of electrodes for neural interface systems. Eur J Transl Myol 2016;26:181-6.

55. Godfraind C, Debelle A, Lonys L, et al. Inductive powering of subcutaneous stimulators: key parameters and their impact on the design methodology. Eur J Transl Myol 2016;26:155-60.

56. Valtin M, Kociemba K, Behling $\mathrm{C}$, et al. RehaMovePro: A versatile mobile stimulation system for transcutaneous FES applications. Eur J Transl Myol 2016;26:203-8.

57. Oliveira A, Ordonez JS, Ashouri Vajari D, et al. Laser-induced carbon pyrolysis of electrodes for 
neural interface systems. Eur J Transl Myol 2016;26:181-6.

58. Aqueveque P, Acuña V, Saavedra V, et al. Power strategy in DC/DC converters to increase efficiency of electrical stimulators. Eur J Transl Myol 2016;26:223-8.

59. Julémont $\mathrm{N}$, Nonclercq A, Delchambre $\mathrm{V}$, Vanhoestenberghe A. A study on cross-talk nerve stimulation: electrode placement and current leakage lid. Eur J Transl Myol 2016;26:239-43.

60. Resquín F, Gonzalez-Vargas J, Ibáñez J, et al. Feedback error learning controller for functional electrical stimulation assistance in a hybrid robotic system for reaching rehabilitation. Eur J Transl Myol 2016;26:255-61.
61. Aqueveque P, Sobarzo S, Saavedra F, et al. Android platform for realtime gait tracking using inertial measurement units. Eur J Transl Myol 2016;26:262-7.

62. Laursen CB, Nielsen JF, Andersen OK, Spaich EG. Feasibility of using Lokomat combined with functional electrical stimulation for the rehabilitation of foot drop. Eur J Transl Myol 2016;26:268-73.

63. Marquez-Chin C, Marquis A, Popovic MR. BCITriggered functional electrical stimulation therapy for upper limb. Eur J Transl Myol 2016;26:274-7.

64. Debelle A, Hermans L, Bosquet M, et al. Soft Encapsulation of Flexible Electrical Stimulation Implant: Challenges and Innovations. Eur J Transl Myol 2016;26:292-6. 